có hai chủ đề lo âu đồng thời (72,58\%) và thời gian tồn tại của triệu chứng trung bình 19,35 \pm 11,26 phút. Tân suất xuất hiện triệu chứng hôi hộp $(82,26 \%)$; chóng mặt $(65,2 \%)$. Ngoài ra triệu chứng tâm thân thường gặp nhất là triệu chứng chóng mặt $(83,87 \%)$ và điểm HAM-A cho nặng chiếm tỉ lệ cao nhất với 53,22\%.

\section{TÀI LIÊU THAM KHẢO}

1. Strawn J.R., Geracioti L., Rajdev N. et al. (2018), "Pharmacotherapy for generalized anxiety disorder in adults and pediatric patients: An evidence-based treatment review", Expert Opin Pharmacother; 19(10): 1057-1070.

2. Gonçalves D.C., Pachana N.A. and Byrne G.J. (2011), Prevalence and correlates of generalized anxiety disorder among older adults in the Australian National Survey of Mental Health and Well-Being", Psychological Medicine; 32, 649-659.

3. Kroenke K., Spitzer R.L., Williams J.B. et al. (2007), "Anxiety disorders in primary care: prevalence, impairment, comorbidity, and detection",
Annals of Internal Medicine; 146, 317-325.

4. Montgomery 0 ., Follen $M$. and UrdanetaHartmann S. (2012), "The 2010 annual sex and gender research forum at drexel university and drexel university college of medicine: an institute for women's health and leadership initiative. Introduction", Gend Med; 9(1 Suppl): 1-6.

5. Trân Nguyễn Ngọc (2018), "Đánh giá hiệu quả điều trị rối loan lo âu lan tỏa bằng liệu pháp thư giãn-luyện tập", Luận án tiến sỹ; Đại học y Hà Nội.

6. Crocq M.A. (2017), "The history of generalized anxiety disorder as a diagnostic category", Dialogues Clin Neurosci; 19(2): 107-116.

7. Gordon B.R., McDowell C.P., Lyons M. et al. (2017), "The effects of resistance exercise training on anxiety: A meta-analysis and metaregression analysis of randomized controlled trials", Sports Med; 47(12): 2521-2532.

8. Srivastava S., Menon V., Kayal S. et al. (2020), "Level of anxiety and depression and its clinical and sociodemographic determinants among the parents of children with cancer undergoing chemotherapy", J Neurosci Rural Pract; 11(4): 530-537.

\title{
ĐÁNH GIÁ HIÊUU QUẢ ĐIỀU TRI DỰ PHÒNG SINH NON Ở THAI PHỤ Có Độ DÀI CỔ TỬ CUNG NGẮN BẲNG PROGESTERONE ĐƯờNG ÂM ĐẠO
}

\author{
Vũ Bá Quyết*, Nguyễn Xuân Họi*, Phan Thị Thu Nga*, \\ Nguyễn Thị Huyền Linh*, Hoàng Phương Ly*

\section{SUMMARY \\ EVALUATION OF THE EFFICACY OF PROPHYLACTIC TREATMENT OF PRETERM BIRTH IN PREGNANT WOMEN WITH A SHORT CERVIX WITH VAGINAL PROGESTERONE}

TÓM TẮT

Mục tiêu: Đánh giá hiệu quả điều trị dự phòng sinh non ở thai phụ có cổ tử cung (CTC) ngắn bằng Progesterone đường âm đạo.Đối tượng và phương pháp nghiên cứu: Nghiên cứu can thiệp không đối chứng. 65 thai phu tuần thai từ 19 tuần -23 tuần 6 ngày đến khám thai tại Bệnh viện Phụ Sản Trung ương được siêu âm đường âm đạo xác đinh có đô dài cổ tử cung $\leq 25 \mathrm{~mm}$ và phù hợp với tiểu chuẩn lựa chọn và tiêu chuẩn loại trừ. Các thai phụ được điều trị dư phòng bằng đăt 1 viên Utrogestan âm đao vào buổi tối liên tuc từ khi thu nhân đến khi thai hết 36 tuần. Kết quả nghiên cứu: ț̉ lê đẻ non $<28$ tuần chiếm $6,1 \%$; dưới 34 tuần $12,3 \%$, dưới 35 tuần $16,9 \%$ và dưới 37 tuần $33,8 \%$. Số thai phu không đẻ non ( $\geq 37$ tuần) là: $66,2 \%$. Tình trạng trẻ sau sinh: $12,3 \%$ trẻ tử vong, $87,7 \%$ trẻ sống khỏe manh; $81,5 \%$ trẻ có cân nặng $\geq 2.500$ gram và $18,5 \%$ trẻ có cân nặng < 2.500 gram. Kết luận: Điều trị dự phòng progesterone cho phụ nữ mang thai có CTC ngắn có hiệu quả giảm tỷ lệ sinh non.

Tư khóa: đẻ non, độ dài cổ tử cung, Progesterone.

*Bệnh viện Phụ Sản Trung ương Chịu trách nhiệm chính: Vũ Bá Quyết Email: Quyetvb2000@yahoo.com Ngày nhân bài: 25.01.2021

Ngày phản biên khoa học: 22.3.2021 Ngày duyệt bài: 30.3.2021
Objective: To evaluate the efficacy of prophylactic treatment of preterm birth in pregnant women with a short cervix with vaginal progesterone. Subjects and research methods: A non-controlled intervention study involved 65 pregnanciesat $19-23$ weeks and 6 days gestation at the National Hospital Obstetrics and Gynecology are determined by vaginal ultrasound to have a length of the cervix $\leq 25 \mathrm{~mm}$ and met the inclusive and exclusive criteria. Pregnant women received prophylactic treatment with 1 tablet vaginal Utrogestan in the evening continuously from enrollment to the end of the 36-week pregnancy. Research results: the rate of preterm birth $<28$ weeks accounted for $6.1 \%$; less than 34 weeks $12.3 \%$, less than 35 weeks $16.9 \%$ and under 37 weeks $33.8 \%$. The number of pregnant women who did not give birth prematurely ( $\geq 37$ weeks) was: $66.2 \%$. Postpartum status: $12.3 \%$ of children die, $87.7 \%$ of children live healthy; $81.5 \%$ of children were $\geq 2,500$ grams and $18.5 \%$ were $<2,500$ grams. Conclusion: Progesterone prophylaxis for pregnant women with a short cervix is effective in reducing the rate of preterm birth.

Keywords: preterm birth, cervical length, Progesterone. 


\section{I. ĐẶT VẤN ĐỀ}

Đẻ non là nguyên nhân hàng đầu gây biến chứng và tử vong chu sinh trên toàn thế giới. Đây là thách thức lớn nhất cho ngành sản khoa hiện nay[1]. Một trong những nguyên nhân gây đẻ non là do giảm hoạt tính của progesterone, dẫn đến sự chín muồi sớm của cổ tử cung (CTC). Độ dài CTC ngắn được xác định qua siêu âm (thời điểm 3 tháng giữa thai kỳ) là một yếu tố tiên lượng của đẻ non tự nhiên. Các thử nghiệm lâm sàng và phân tích gộp đã cho thây Progesterone đặt âm đạo làm giảm tỷ lệ sinh non và bệnh tật ở trẻ sơ sinh[2, 3]. Chính vì vậy, chúng tôi tiến hành nghiên cứu với mục tiểu: Đánh giá hiệu quả dự phòng sinh non bằng Progesterone đường âm đạo.

\section{II. ĐỐI TƯợNG VÀ PHƯƠNG PHÁP NGHIÊN CỨU}

2.1 Đối tượng nghiên cứu. Các thai phụ đến khám thai tại Bệnh viện Phụ Sản Trung ương có tuổi thai từ 19 đến 23 tuần 6 ngày. Lựa chọn các thai phụ có kết quả siêu âm độ dài CTC $\leq 25 \mathrm{~mm}$, phù hợp với tiêu chuẩn lựa chọn và tiêu chuẩn loại trừ để đưa vào nghiên cứu.

Tiêu chuẩn lựa chọn

- Tuổi thai từ 19 tuần đến 23 tuần 6 ngày
- Đơn thai, thai đang phát triển. $25 \mathrm{~mm}$.

- Độ dài cổ tử cung siêu âm qua âm đạo $\leq$

- Không có các triệu chứng của chuyển da sinh non.

- Tự nguyện tham gia nghiên cứu

\section{Tiêu chuẩn loại trừ}

- Thai bênh lý, bất thường hình thái

- Thai phụ đang được điều trị Progesterone hoặc điều trị Progesterone trước đó 2 tuần.

- Rỉ ối, ối võ non

- Thai phụ đã được khâu vòng cổ tử cung.

- Thai phụ có tiên sử phẫu thuật vùng cổ tử cung

- Thai phụ có tình trạng bệnh lý: Tim mạch, hen, tăng huyết áp, tiền sản giật...

- Các bệnh lý của tử cung: Tử cung đôi, tử cung hai sừng...

\subsection{Phương pháp nghiên cứu}

- Thiết kế nghiên cứu:Nghiên cứu can thiệp không đối chứng

- Cỡ mẫu nghiên cứu: 65 thai phụ có độ dài cổ tử cung $\leq 25 \mathrm{~mm}$.

- Phương tiện nghiên cứu: sử dụng Progesterone có biệt dược là Utrogestan hàm lượng 200mg.

Các bước thực hiện:

\begin{tabular}{|c|c|}
\hline \multicolumn{2}{|c|}{$\begin{array}{l}\text { Thai phụ đơn thai có tuổi thai } 19-23 \text { tuần } 6 \text { ngày } \\
\text { Siêu âm có độ dài CTC } \leq 25 \mathrm{~mm}\end{array}$} \\
\hline \multicolumn{2}{|c|}{$\begin{array}{l}\text { Điều trị dự phòng sinh non bằng Utrogestan đướng âm đạo với liều } 1 \text { viên/ngày cho thai phụ có } \\
\text { CTC } \leq 25 \mathrm{~mm} \text {; Thời điểm điều trị tữ khi phát hiện CTC } \leq 25 \mathrm{~mm} \text { đến tuối thai hết } 36 \text { tuần }\end{array}$} \\
\hline \multicolumn{2}{|c|}{ Theo dõi điều trị } \\
\hline \multirow{2}{*}{\multicolumn{2}{|c|}{\begin{tabular}{l|l} 
- Khám lại 2 tuần/lân & \\
- Khám thai & Siêu \\
- Khám viêm nhiễm đường sinh dục dưới & - Xé \\
- Đánh giá tác dụng phụ của thuốc & - So \\
- Tư vấn điều trị & \\
\end{tabular}}} \\
\hline & \\
\hline $\begin{array}{c}\text { Có dấu hiệu dọa sinh non, nhập viện điều trị } \\
\text { dọa sinh non theo phác đồ thường quy của } \\
\text { bệnh viện }\end{array}$ & $\begin{array}{c}\text { Tiếp tục điều trị dự phòng sinh non bằng } \\
\text { Utrogestan đến hết tuần } 36 \text { thai kỳ nếu điều trị } \\
\text { dọa sinh non thành công }\end{array}$ \\
\hline \multicolumn{2}{|c|}{$\downarrow$} \\
\hline \multicolumn{2}{|c|}{$\begin{array}{l}\text { Chuyển dá } \\
\text { - Cách thức sinh } \\
\text { - Cân nặng, chỉ số apgar } \\
\text { - Bệnh tật trẻ sơ sinh, các can thiệp } \\
\text { - Tứ vong trẻ sơ sinh }\end{array}$} \\
\hline
\end{tabular}

\section{KẾT QUẢ NGHIÊN CỨU VÀ BÀN LUẬN}

\subsection{Tuổi của đối tượng nghiên cứu}




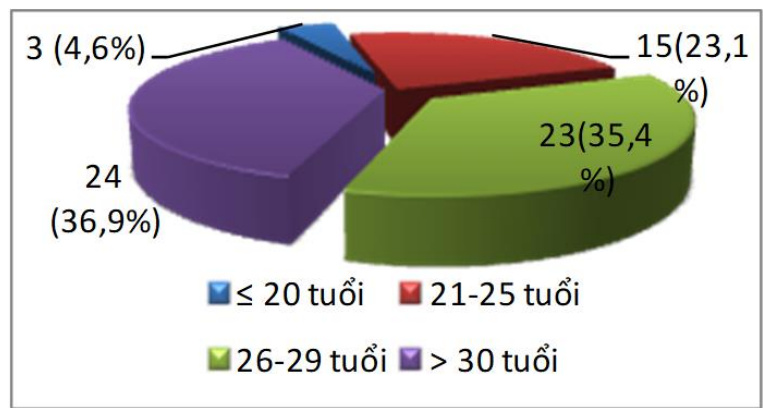

Biểu đồ 1. Tuổi của đôî tượng nghiên cứu

Tuổi trung bình trong nhóm nghiên cứu của chúng tôi là $29 \pm 5,2$ tuổi, tuổi thấp nhất là 19 tuổi và tuổi cao nhất là 39 tuổi. Theo nghiên cứu của Hassan [4] độ tuổi trung bình của thai phụ

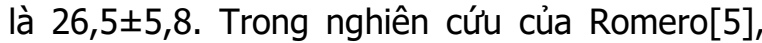
độ tuổi trung bình của thai phụ là 27 tuổi, tuổi nhỏ nhất là 25 và cao tuổi nhất là 30 tuổi. Kết quả nghiên cứu này của chúng tôi cao hơn nghiên cứu của Hassan và Romero, tuy nhiên thấp hơn nghiên cứu của Norman [6] đô tuổi trung bình là $31,5 \pm 5,6$. Sư phân bố tuổi của thai phụ tập trung chủ yếu vào nhóm tuổi từ 2534 tuổi, tương tự như các nghiên cứu của các tác giả nước ngoài. Độ tuổi này là độ tuổi chủ yếu trong độ tuổi kết hôn và sinh đẻ của xã hội cho nên tỷ lệ mang thai ở nhóm tuổi này cao hơn các nhóm tuổi khác.

\section{2. Độ dài CTC trung bình theo tuân thai} Bảng 1. Độ dài CTC trung bình theo tuần thai

\begin{tabular}{|c|c|c|c|c|c|}
\hline $\begin{array}{l}\text { Tuấn } \\
\text { thai }\end{array}$ & $\begin{array}{c}\text { Số } \\
\text { lượng }\end{array}$ & $\begin{array}{l}\text { Độ dài trung bình } \pm \text { độ } \\
\text { lệch chuẩn }(\mathrm{mm})\end{array}$ & Min (mm) & $\operatorname{Max}(\mathbf{m m})$ & $\mathbf{P}$ \\
\hline 19 & 8 & $22,5 \pm 2,5$ & 17,6 & 25 & \multirow{5}{*}{0,08} \\
\hline 20 & 7 & $19,3 \pm 6,2$ & 10,1 & 25 & \\
\hline 21 & 12 & $22,3 \pm 4$ & 10 & 25 & \\
\hline 22 & 23 & $21,5 \pm 3,6$ & 13 & 25 & \\
\hline 23 & 12 & $19,2 \pm 4,5$ & 10,7 & 24 & \\
\hline \multicolumn{2}{|c|}{ Trung bình } & \multicolumn{4}{|c|}{$21,1 \pm 4,1$} \\
\hline
\end{tabular}

Độ dài CTC trung bình của 65 thai phụ là $21,1 \pm 4,1 \mathrm{~mm}$. Độ dài CTC ngắn nhất là $10,1 \mathrm{~mm}$. Độ dài CTC trung bình giữa các tuần thai không có sự khác biệt có ý nghĩa thống kê với $p=0,08$.

3.3. Tuổi thai khi chuyển dạ đẻ Bảng 2. Tuổi thai khi chuyển dạ đẻ

\begin{tabular}{|c|c|c|}
\hline Tuổi thai & $\begin{array}{c}\text { Số lượng } \\
\text { (n=65) }\end{array}$ & $\begin{array}{c}\text { Tỷ } \mathbf{~ l e ̣ ̂ ~} \\
\text { \% }\end{array}$ \\
\hline Đẻ non $<28$ tuần & 4 & 6,1 \\
\hline Đẻ non $<30$ tuần & 6 & 9,2 \\
\hline Đẻ non $<32$ tuần & 7 & 10,8 \\
\hline Đẻ non $<34$ tuần & 8 & 12,3 \\
\hline Đẻ non < 35 tuần & 11 & 16,9 \\
\hline Đẻ non < 37 tuần & 22 & 33,8 \\
\hline
\end{tabular}

Trong số 65 thai phụ điều trị dự phòng progesterone, tỷ lệ đẻ non <28 tuần chiếm 6,1\%; dưới 34 tuần 12,3\%, dưới 35 tuần 16,9\% và dưới 37 tuần $33,8 \%$. Số thai phụ không đẻ non (tuổi thai khi sinh $\geq 37$ tuần) là: $66,2 \%$.

Theo 2 nghiên cứu Phân tích tổng hợp của Fonseca và cs 2007[7]; O' Brien [8]và cs 2007; Rode và cS 2011[9]; Hassan và CS 2011[4]; Cetingoz và cs 2011 trên 723 phụ nữ và phân tích tổng hợp của R. Romero và CS 2016 trên 974 phụ nữ là những nghiên cứu thử nghiệm lâm sàng có nhóm chứng và đã đưa ra được các kết luận progesterone đặt âm đạo làm giảm đáng kể nguy cơ sinh non $<28$ tuần, < 34 tuần và < 36 tuần so với nhóm dùng giả dược. Nguy cơ sinh non $\leq 34$ tuần tuổi thai hoặc tử vong thai nhi so với giả dược $(18,1 \%$ so với $27,5 \%$;
$\mathrm{RR}=0,66 ; \mathrm{KTC} 95 \% \mathrm{CI}: 0,52-0,83) ; \mathrm{P}=$ 0,0005; năm nghiên cứu; 974 phụ nứ). Nguy cơ sinh non xảy ra ở tuần thai $<28$ đến $<36$ (RR từ 0,51 đến 0,79 ), hội chứng suy hô hấp ( $R R=$ 0,47; KTC $95 \%=0,27-0,81$ )[3].

\subsection{Một số đặc điểm khi chuyển dạ}

Bảng 3. Mốt số đăc điểm khi chuyển da \begin{tabular}{|c|c|c|}
\hline Đặc trưng & Số lượng (n=65) & Tỷ lệ \% \\
\hline
\end{tabular}

\begin{tabular}{|c|c|c|}
\hline \multirow{2}{*}{\multicolumn{3}{|c|}{$\ldots$}} \\
\hline & & \\
\hline Có & 14 & 21,5 \\
\hline Không & 51 & 78,5 \\
\hline \multicolumn{3}{|c|}{ Truyên Oxytocin } \\
\hline Có & 14 & 21,5 \\
\hline Không & 51 & 78,5 \\
\hline \multicolumn{3}{|c|}{ Giảm đau trong đẻ } \\
\hline Có & 38 & 58,5 \\
\hline Không & 27 & 41,5 \\
\hline \multicolumn{3}{|c|}{ Cách đẻ } \\
\hline Đẻ thường & 40 & 61,5 \\
\hline Đẻ mố & 24 & 36,9 \\
\hline Đẻ thủ thuật & 1 & 1,5 \\
\hline
\end{tabular}

Đặc điểm của sản phụ khi chuyển dạ: Có 2 trường hợp sản khoa dẫn đến sinh non: (1) sinh non xảy ra sau khi bắt đầu chuyển dạ tự nhiên (vỡ ối hoặc còn nguyên màng ối) hoặc (2) sinh non được chỉ định xảy ra do các biến chứng của mẹ hoặc bệnh của thai nhi. Trong nghiên cứu này 
có 14 sản phu chiếm tỷ lệ $21,5 \%$ võ ối trước khi chuyển dạ. Truyền Oxytocin có 14 sản phụ chiếm tỷ lệ $21,5 \%$, có 38 sản phụ $(58,5 \%)$ sử dụng giảm đau trong đẻ. Trong số trẻ sinh ra có 31 trẻ trai (chiếm tỷ lê $47,7 \%$ ) và 34 trẻ gái (chiếm tỷ lê $52,5 \%$ ). Trong số 65 sản phụ, có 40 sản phụ đẻ thường chiếm tỷ lệ cao nhất $61,5 \%$. Đẻ mổ có 24 trường hợp chiếm tỷ lệ 36,9\%. Có 01 trường hợp sử dụng forcep chiếm tỷ lệ 1,5\%. Theo đánh giá của Hassan và cộng sự năm 2011 một nghiên cứu thử nghiệm đa trung tâm, ngẫu nhiển, mù đôi có đối chứng về progesterone âm đạo làm giảm tỷ lệ sinh non ở phụ nữ có cổ tử cung ngắn trên siêu âm có kết luận về dữ liệu chuyển dạ, sinh con và cách đẻ là không có sự khác biệt có ý nghĩa thông kê về phương pháp sinh[4].

\subsection{Một số đắc điểm của trẻ sơ sinh} Bảng 4. Một số đặc điểm củatrẻ sơ sinh \begin{tabular}{|l|l|l|}
\hline Đặc trưng & Số lượng $(n=65)$ & Tỷ lệ \% \\
\hline
\end{tabular}

\begin{tabular}{|c|c|c|}
\hline \multicolumn{3}{|c|}{ Giới tính } \\
\hline Nam & 31 & 47,7 \\
\hline Nữ & 34 & 52,5 \\
\hline \multicolumn{3}{|c|}{ Trọng lượng thai } \\
\hline$<2500$ gram & 12 \\
\hline$\geq 2500$ gram & 53 & 18,5 \\
\hline \multicolumn{3}{|c|}{ Tình trạng } \\
\hline Sống & 57 & 81,5 \\
\hline Tữ vong & 8 & 87,7 \\
\hline
\end{tabular}

Trọng lượng thai nhi < 2500 gram có 12 trẻ chiếm tỷ lệ $18,5 \%$. Trọng lượng thai nhi $\geq 2500$ gram có 53 trẻ chiếm tỷ lệ $81,5 \%$. Có 57 trẻ xuất viện khỏe mạnh chiếm tỷ lệ $87,7 \%$. Có 8 trẻ sơ sinh tử vong sau sinh do các trẻ sinh non phải thở máy (07 trẻ) và xẹp phổi (01 trẻ).

Trong nghiên cứu này, 13 thai phụ có tiền căn sinh non: trong 13 trường hợp có tiền căn sinh non có 3 trường hợp sinh non trong lần mang thai này. Tình trạng sinh sống, tử vong và cân nặng của trẻ sơ sinh: Trong 65 trường hợp, có 8 trường hợp tử vong (12,3\%). 12/65 thai nhi có trọng lượng thai < 2500gram $(18,5 \%)$.

Phân tích gộp các nghiên cứu ngẫu nhiên kết luận bổ sung progesterone làm giảm khả năng tái phát sinh non và cải thiện kết cục của trẻ sơ sinh. Trong năm 2013, một phân tích gộp trên 36 nghiên cứu về những sản phụ có tiền căn sinh non cho thấy lợi ích bổ sung progesterone so với nhóm placebo hay không điều trị: Tử vong so sinh (RR = 0,45; KTC 95\% CI: 0,27-0,76). Sử dung hố trơ thở (RR = 0,40; KTC 95\% CI 0,18$0,90)$. Xuất huyết não thất, nhiễm trùng sơ sinh và bệnh về mắt không có khác biết có ý nghĩa thống kê. Nghiên cứu của Hassan và cộng sự từ 2008-2010 ở 458 sản phụ có kết luận: ở phụ nữ không có tiền sử sinh non, dùng progesterol âm đạo có liên quan đến việc giảm đáng kể tỷ lệ sinh non trước 33 tuần $(7,6 \%)$ so với $(15,3 \%)$; $\mathrm{RR}=0,50 ; \mathrm{KTC} 95 \%: 0,27-0,90 ; \mathrm{p}=0,02$. Tuy nhiên, việc giảm tỷ lệ sinh non ở phụ nữ có tiền sử sinh non từ 20 đến 34 tuần tuổi thai không đạt ý nghĩa thống kê $(15,8 \%$ so với 20,6 ; RR 0,77; KTC 95\%; 0,29-2,06; $\mathrm{P}=0,6)[4]$.

\section{KẾT LUẬN}

- Điều trị dự phòng progesterone cho phụ nữ mang thai có CTC ngắn có hiệu quả giảm tỷ lệ sinh non: tỷ lệ đẻ non <28 tuần chiếm $6,1 \%$; dưới 34 tuần $12,3 \%$, dưới 35 tuần $16,9 \%$ và dưới 37 tuần 33,8\%. Số thai phụ không đẻ non ( $\geq 37$ tuần) là: $66,2 \%$.

- Tình trạng trẻ sau sinh: $12,3 \%$ trẻ tử vong, $87,7 \%$ trẻ sônng khỏe mạnh; $81,5 \%$ trẻ có cân nặng $\geq 2.500$ gram và $18,5 \%$ trẻ có cân nặng < 2.500 gram.

\section{TÀI LIẸU THAM KHẢO}

1. Blencowe $H$, Cousens $S$, Oestergaard $M Z$, Chou D, Moller AB, Narwal $R$, et al. National, regional, and worldwide estimates of preterm birth rates in the year 2010 with time trends since 1990 for selected countries: a systematic analysis and implications. Lancet (London, England). 2012;379(9832):2162-72.

2. Romero R. Vaginal progesterone to reduce the rate of preterm birth and neonatal morbidity: a solution at last. Women's health (London, England). 2011;7(5):501-4.

3. Romero $\mathbf{R}$, Nicolaides $\mathbf{K H}$, Conde-Agudelo $\mathbf{A}$ O'Brien JM, Cetingoz E, Da Fonseca E, et al. Vaginal progesterone decreases preterm birth $\leq 34$ weeks of gestation in women with a singleton pregnancy and a short cervix: an updated meta-analysis including data from the OPPTIMUM study. Ultrasound in obstetrics \& gynecology: the official journal of the International Society of Ultrasound in Obstetrics and Gynecology. 2016;48(3):308-17.

4. Hassan SS, Romero R, Vidyadhari D, Fusey S, Baxter JK, Khandelwal $M$, et al. Vaginal progesterone reduces the rate of preterm birth in women with a sonographic short cervix: a multicenter, randomized, double-blind, placebocontrolled trial. Ultrasound in obstetrics \& gynecology : the official journal of the International Society of Ultrasound in Obstetrics and Gynecology. 2011;38(1):18-31.

5. Romero $R$, Conde-Agudelo $A$, El-Refaie $\mathbf{W}$, Rode L, Brizot ML, Cetingoz E, et al. Vaginal progesterone decreases preterm birth and neonatal morbidity and mortality in women with a twin gestation and a short cervix: an updated meta-analysis of individual patient data. Ultrasound in obstetrics \& gynecology: the official journal of the International Society of Ultrasound in Obstetrics and Gynecology. 2017;49(3):303-14.

6. Norman JE, Marlow N, Messow C-M, 
Shennan A, Bennett PR, Thornton S, et al. Vaginal progesterone prophylaxis for preterm birth (the OPPTIMUM study): a multicentre, randomised, double-blind trial. Lancet (London, England). 2016;387(10033):2106-16.

7. Fonseca EB, Celik E, Parra $M$, Singh $M_{\text {, }}$ Nicolaides KH. Progesterone and the risk of preterm birth among women with a short cervix. The New England journal of medicine. 2007:357(5):462-9.

8. O'Brien JM, Adair CD, Lewis DF, Hall DR, Defranco EA, Fusey $S$, et al. Progesterone vaginal gel for the reduction of recurrent preterm birth: primary results from a randomized, doubleblind, placebo-controlled trial. Ultrasound in obstetrics \& gynecology : the official journal of the International Society of Ultrasound in Obstetrics and Gynecology. 2007;30(5):687-96.

9. Rode $L$, Klein $K$, Nicolaides KH, KramplBettelheim E, Tabor A. Prevention of preterm delivery in twin gestations (PREDICT): a multicenter, randomized, placebo-controlled trial on the effect of vaginal micronized progesterone. Ultrasound in obstetrics \& gynecology : the official journal of the International Society of Ultrasound in Obstetrics and Gynecology. 2011;38(3):272-80.

\section{KẾT QUẢ ĐÎ̂̀U TRI VI PHẪU THUÂT PHÌNH ĐộNG MẠCH NÃO GIŨ̃A TẠI BÊ̂NH VIỆN VIỆT ĐỨC}

\section{TÓM TẮT}

Mục tiêu: Đánh giá kết quả điều trị phẫu thuật túi phình động mạch não giữa.Đối tượng và phương pháp nghiên cứu: Nghiên cứu hồi cứu 35 bệnh nhân được chẩn đoán và điêu trị phẫu thuâat phình động mạch não giữa tại bệnh viện Việt Đức từ 12.2016 đến 9.2019. Kết quả: tuổi trung bình của bệnh nhân $(50,08 \pm 14,58)$; nữ/nam $=1,7$; đau đầu là triệu chứng thường gặp nhất $(85,71 \%) ; 80 \%$ số bệnh nhân có GCS $\geq 13 ; 71,05 \%$ số túi phình đã võ̃; Điều trị phấu thuât bao gồm kep trực tiếp phình mach; phấu thuật bắc câu động mạch trong và ngoài sọ kết hợp với kẹp phình hoăc can thiêp mạch. Kết luân: phẫu thuật điều trị phình động mạch não giữa là phương pháp an toàn, có hiệu quả.

\section{SUMMARY}

\section{THE RESULTS OF SURGICAL TREATMENT OF MIDDLE CEREBRAL ANEURYSMS AT VIET-DUC HOSPITAL}

Objective: assessment of the result of surgical treatment of middle cerebral aneurysms. Patients and methods: A cross-section, retrospective study with 35 patients diagnosed and surgically treated at Viet-Duc hospital from Dec 2016 to September 2019. Results: The patient's mean age was $50.08 \pm 14,58$; female/male ratio was 1.7; headache was the most common symptom. There was eighty percent of patients who had GCS more than 13 . Seventy-one point zero-five percent of aneurysms were ruptured. Surgical treatments were direct clip, extracranial-intracranial bypass surgery combined clip, or endovascular therapy. Conclusion: Surgery was the usefulness and safety for the middle cerebral aneurysms.

\section{*Bênh viện Viêtt Đức}

Chiu trách nhiệm chính: Ngô Manh Hùng

Email: ngomanhhung2000@gmail.com

Ngày nhận bài: 18.01.2021

Ngày phản biên khoa hoc: 18.3.2021

Ngày duyệt bài: 26.3.2021
Ngô Mạnh Hùng*

\section{I. ĐĂT VẤN ĐỀ}

Phình động mạch não là nguyên nhân hàng đầu gây ra chảy máu dưới nhện Phình động mạch não giữa là dạng thường gặp nhất của túi phình động mạch não. Điều trị phình động mạch não bao gồm: điều trị phẫu thuật, điều trị can thiêp mach và điều tri nôi khoa. Mắc dù can thiệp nội mạch ngày càng trở nên phổ biến, song túi phình động mạch não giữa vẫn là một trong các chỉ định của phẫu thuật [1], đặc biệt trong hoàn cảnh Việt nam, khi mà can thiệp nội mạch chưa thể sử dụng cho mọi bệnh nhân. Chúng tôi tiến hành nghiên cứu này với mục đích đánh giá kết quả điều trị phẫu thuật túi phình động mạch não giữa trong thời gian gần đây.

\section{II. ĐỐI TƯỢNG VÀ PHƯƠNG PHÁP NGHIÊN CỨU}

Nghiên cứu gồm 35 bệnh nhân được chẩn đoán và điều trị phẫu thuât phình động mach não giữa tại bệnh viện Việt Đức từ 12.2016 đến 6.2019.

\section{Tiêu chuẩn lựa chọn}

- Bệnh nhân được chẩn đoán phình động mach não giữa

- Đã được điều tri phẫu thuât xử lý túi phình

- Tham gia theo dõi sau mổ ít nhất là 12 tháng.

\section{Tiêu chuẩn loai trừ}

- Bệnh nhân không có ít nhất một trong các tiêu chuẩn lựa chọn bênh nhân

Phương pháp nghiên cứu: hồi cứu, mô tả, cắt ngang

Các biến số nghiên cứu: tuổi, giới, tiền sử bệnh, triệu chứng lâm sàng, đặc điểm hình ảnh học của phình động mạch não, phương pháp phẫu thuật, kết quả lâm sàng và chẩn đoán hình ảnh sau mổ. 